Portland State University

PDXScholar

$1-1-2000$

\title{
Molecular interaction between nitric oxide and ryanodine receptors of skeletal and cardiac sarcoplasmic reticulum
}

Guy Salama

Elizaveta V. Menshikova

Jonathan J. Abramson

Follow this and additional works at: https://pdxscholar.library.pdx.edu/phy_fac

Part of the Physics Commons

Let us know how access to this document benefits you.

\section{Citation Details}

Salama, G., Menshikova, E., \& Abramson, J. (2000). Molecular interaction between nitric oxide and ryanodine receptors of skeletal and cardiac sarcoplasmic reticulum. Antioxidants \& Redox Signaling, 2(1), 5-16.

This Article is brought to you for free and open access. It has been accepted for inclusion in Physics Faculty Publications and Presentations by an authorized administrator of PDXScholar. Please contact us if we can make this document more accessible: pdxscholar@pdx.edu. 


\title{
Forum Minireview
}

\section{Molecular Interaction Between Nitric Oxide and Ryanodine Receptors of Skeletal and Cardiac Sarcoplasmic Reticulum}

\author{
GUY SALAMA, ${ }^{1}$ ELIZAVETA V. MENSHIKOVA, ${ }^{1}$ and JONATHAN J. ABRAMSON ${ }^{2}$
}

\begin{abstract}
In striated muscle, the sarcoplasmic reticulum (SR) is the major storage compartment of intracellular $\mathrm{Ca}^{2+}$ that controls cytosolic free $\mathrm{Ca}^{2+}$ (Cai) and developed force by sequestering and releasing $\mathrm{Ca}^{2+}$ during each contraction. $\mathrm{Ca}^{2+}$ release from the SR occurs through high-conductance $\mathrm{Ca}^{2+}$ release channels or ryanodine receptors (RyR), which are regulated by various signaling processes. Over the last 15 years, there has been a growing consensus that critical sulfhydryl sites on RyRs can be oxidized and reduced, respectively, to open and close the release channels. The pharmacological actions of various classes of sulfhydryl reagents have demonstrated the existence of hyperreactive thiols on RyRs, which could play a role in the regulation of normal contractile function and explain contractile dysfunctions in pathological conditions. More recent studies show that redox regulation of release channels may occur by nitric oxide (NO), a physiological signaling mechanism. This article is intended to review current concepts in thiol regulation of RyRs and present new data on the possible identification of the primary cysteine residues, which may be the site of oxidation and S-nitrosylation involved in channel opening. Antiox. Redox Signal. 2, 5-16.
\end{abstract}

\section{INTRODUCTION}

$F^{\circ}$ ORCE GENERATION in muscle is regulated by the cytosolic level of ionized calcium (Cai). In striated muscle, the sarcoplasmic reticulum (SR) is the intracellular compartment from which $\mathrm{Ca}^{2+}$ release and re-uptake produces muscle twitches. A central question is the mechanism coupling the firing of an action potential at the plasma membrane to the release of $\mathrm{Ca}^{2+}$ from the SR network. The SR $\mathrm{Ca}^{2+}$ release channel was identified by several laboratories as a high-molecular-weight protein
$\left(M_{r} \sim 565 \mathrm{kDa}\right)$ through its high-affinity binding to ryanodine (Pessah et al., 1987). The ryanodine receptor complex (RyR) was purified from junctional or heavy SR proteins using radiolabeled ryanodine and linear sucrose gradients (Lai et al., 1988). The RyR was first cloned and sequenced from rabbit skeletal muscle, and the functional channel was found to consist of homologous tetramers with subunits of $\sim 5,000$ amino acid residues (Takeshima et al., 1989). Reconstitution of RyRs in planar bilayers revealed a channel with pharmacological properties similar to those described for $\mathrm{Ca}^{2+}$ re-

\footnotetext{
${ }^{1}$ Department of Cell Biology and Physiology, University of Pittsburgh, School of Medicine, Pittsburgh, Pennsylvania 15261.

${ }^{2}$ Physics Department, Portland State University Portland, Oregon 97207.
} 
lease from skinned fibers, SR vesicles, and reconstituted 'native' SR channels through the fusion of SR vesicles with planar bilayers (Smith et al., 1988). In addition to the traditional activators of $\mathrm{SR} \mathrm{Ca}^{2+}$ release, we have demonstrated that several types of sulfhydryl reagents elicit a rapid release of $\mathrm{Ca}^{2+}$ by activating $\mathrm{Ca}^{2+}$ release channels on the SR of skeletal and cardiac muscles.

\section{HEAVY METALS}

Heavy metals (e.g., $\mathrm{Hg}^{2+}, \mathrm{Ag}^{+}, \mathrm{Cu}^{2+}, \mathrm{Cd}^{2+}$, $\mathrm{Zn}^{2+}$ ) were shown to induce $\mathrm{Ca}^{2+}$ release from $\mathrm{SR}$ vesicles by binding to an accessible free sulfhydryl group (SH) on an SR protein (Abramson et al., 1983). The concentration of heavy metals used to elicit rapid and complete release of $\mathrm{Ca}^{2+}$ were too low to affect the $\mathrm{Ca}^{2+}, \mathrm{Mg}^{2+}$-ATPase, and their potency was similar to their relative binding affinity to $\mathrm{SH}$ groups. More detailed experiments revealed that $\mathrm{Ag}^{+}$-induced $\mathrm{Ca}^{2+}$ release was selective for terminal SR rather than for longitudinal SR, and that at low concentrations $\mathrm{Ag}^{+}$selectively acted at $\mathrm{Ca}^{2+}$-release channels of skeletal SR and not $\mathrm{Ca}^{2+}, \mathrm{Mg}^{2+}$-ATPase pumps (Salama and Abramson, 1984). The site of action was challenged by Gould et al. (1987), who reported that $\mathrm{Ag}^{+}$elicited release from $\mathrm{Ca}^{2+}$ pumps reconstituted in liposomes. However, the purity of their preparation was not assessed, no attempts were made to modify the $\mathrm{Ag}^{+}$effect by agents known to modulate $\mathrm{SR} \mathrm{Ca}^{2+}$ release, and the ratio of $\mathrm{Ag}^{+}$to protein was 5-10 times greater than that used in SR vesicle experiments. We confirmed our studies with heavy metals with cardiac SR vesicles (Prahbu and Salama, 1990b) and skinned psoas fibers (Salama et al., 1992), and used rapid filtration techniques to characterize the kinetics of $\mathrm{Ag}^{+}$induced $\mathrm{Ca}^{2+}$ release (Moutin et al., 1989). The rate of $\mathrm{Ag}^{+}$-induced $\mathrm{Ca}^{2+}$ release was as rapid as that for $\mathrm{Ca}^{2+}$-induced $\mathrm{Ca}^{2+}$ release and had a bell shape relationship as a function of $\mathrm{Ag}^{+}$ concentration that was right shifted with increasing pCa (Moutin et al., 1989). These data suggested a common process shared by $\mathrm{Ag}^{+}$ and $\mathrm{Ca}^{2+}$ as they interact with RyRs to regulate $\mathrm{Ca}^{2+}$ release (Moutin et al., 1989). Other groups reported data supporting our interpretation that heavy metals acted at "critical" sulfhydryl sites to elicit SR $\mathrm{Ca}^{2+}$ release. Palade (1987) tested numerous agents for their relative potency at eliciting $\mathrm{SR} \mathrm{Ca}^{2+}$ release, their selectivity of action at terminal cisternae compared to longitudinal SR, and their blockage by known inhibitors of $\mathrm{Ca}^{2+}$ release. $\mathrm{Ag}^{+}$was found to be the most potent at triggering release $(<\mu M)$ and had the highest level of discrimination between heavy and light SR (Palade, 1987). $\mathrm{Ag}^{+}$was found to dissociate ryanodine from its high-affinity binding site in minutes (Pessah et al., 1987).

$\mathrm{Ag}^{+}$and $\mathrm{Hg}^{2+}$ also induce $\mathrm{Ca}^{2+}$ release from the SR network of skinned frog fibers and act by binding to sulfhydryl sites on $\mathrm{Ca}^{2+}$ release channels (Aoki et al., 1985; Oba et al., 1989). In intact frog skeletal fibers, $\mathrm{Ag}^{+}$elicited contractions by a complex mechanism that may involve an interaction with voltage-gated $\mathrm{Ca}^{2+}$ channels on T tubules (Oba and Hotta, 1985). In mammalian skeletal fibers, heavy metals were shown to trigger $\mathrm{Ca}^{2+}$ release from the $\mathrm{SR}$ network of skinned psoas fibers by a process that was inhibited by agents known to inhibit the activation of ryanodine receptors (Salama et al., 1992). An important conclusion that can be derived from these studies is that heavy metals interact preferentially with sulfhydryl sites that alter $\mathrm{SR} \mathrm{Ca}^{2+}$ release channels, even in the presence of other protein thiols located on the $\mathrm{SR}$, enzymes, and contractile proteins. Heavy metals are interesting from a toxicology point of view, but they are not physiological triggers of SR $\mathrm{Ca}^{2+}$ release. Hence, other sulfhydryl reagents were investigated to test for reversible oxidation-reduction of free protein thiols that might be involved in opening and closing $\mathrm{Ca}^{2+}$ release channels.

\section{OXIDIZING AGENTS}

Initial attempts to identify possible physiologically relevant oxidizing agents that might act at RyRs showed that several non-metal-containing porphyrins (Abramson et al., 1993) and quinones (Abramson et al., 1988a; Feng et al., 1999) were potent activators of $\mathrm{Ca}^{2+}$ release, ryanodine binding, and single-channel activity. 
The structurally similar phthalocyanine dye alcian blue was also shown to activate $\mathrm{SR} \mathrm{Ca}^{2+}$ release (Abramson et al., 1988b). Prior reduction of these reagents eliminated their ability to activate the $\mathrm{Ca}^{2+}$ release channel. The high sensitivity of RyRs to oxidation was further demonstrated using various reactive $\mathrm{O}_{2}$ species, which were shown to activate $\mathrm{Ca}^{2+}$ release at low concentrations, and irreversibly inactivate the RyR at high concentrations. These studies examined the effects of singlet $\mathrm{O}_{2}$ (Stuart et al., 1992; Xiong et al., 1992), and peroxide (Favero et al., 1995).

\section{THIOL REAGENTS}

Mercaptans (i.e., the amino acids cysteine, cystamine, and homocysteine) had no effect on $\mathrm{Ca}^{2+}$ uptake or release except in the presence of catalytic concentrations of $\mathrm{Cu}^{2+}(0.5-5 \mu M)$ mercaptans elicited SR $\mathrm{Ca}^{2+}$ release (Trimm et al., 1986). The chemical reaction underlying $\mathrm{Ca}^{2+}$ release induced by cysteine plus $\mathrm{Cu}^{2+}$ indicated that in the closed state, the $\mathrm{Ca}^{2+}$ release channel contains free $\mathrm{SH}$ groups that do not react with exogenously added thiols. However, the addition of a catalyst like $\mathrm{Cu}^{2+}$ promotes the oxidation of the fixed protein thiols on the $\mathrm{Ca}^{2+}$ release channel to form mixed disulfide bonds with the exogenously added cysteine (Cavallini et al., 1969). The formation of mixed disulfide bonds resulted in the opening of the channel and SR $\mathrm{Ca}^{2+}$ release. Consistent with this interpretation, the subsequent addition of a sulfhydryl reducing agent, such as dithiothreitol (DTT) or reduced glutathione (GSH), reduced the disulfide bonds and regenerated free thiols on the channel, promoting channel closure and active $\mathrm{Ca}^{2+}$ re-uptake by SR vesicles (Trimm et al., 1986).

\section{REACTIVE DISULFIDE COMPOUNDS}

An alternative chemical reaction that oxidizes free protein thiols is a sulfhydryl-disulfide interchange reaction, which does not require the presence of a heavy-metal catalyst. In this case, the protein thiol attacks the disulfide bond of an exogenously added reagent, result- ing in the formation of a new disulfide bond between the protein and the added reagent. Sulfhydryl-disulfide interchange reactions typically have slow reaction times and require high substrate concentrations, except for a class of compounds called reactive disulfides (RDS). RDS are compounds with a pyridyl ring adjacent to disulfides like $2,2^{\prime}$-dithiodipyridine $\left(2,2^{\prime}\right.$ DTDP) and 4,4'-dithiodipyridine (4,4'DTDP), which are known to be absolutely specific to free sulfhydryls. They oxidize free sulfhydryls via sulfhydryl-disulfide interchange at high reaction rates and low substrate concentrations. RDS possess an important property that enables them to discriminate in favor of protein thiols with low $\mathrm{pKa}$ values to label any thiol group, even in acidic media. As stated by Brocklehurst (1979), "2-pyridyl disulphides possess not only essentially absolute specificity for thiol groups but, as a result of their two-protonic-state electrophilic character, can permit the selective modification of particular types of thiol groups even in the presence of other thiol groups." In line with their well-established chemistry, the reactive disulfides, 2,2'DTDP and 4,4'DTDP oxidized the channel by forming disulfide bonds, resulting in $\mathrm{SR} \mathrm{Ca}^{2+}$ release in isolated vesicles and the stoichometric release of one thiopyridone per oxidized thiol on SR proteins (Zaidi et al., 1989a). The absorption of thiopyridone differs markedly from that of its parent RDS compound and was used to demonstrate that only $2-4 \%$ of available free thiols on SR proteins were oxidized by RDS (Zaidi et al., 1989a,b). There are 185-200 nmoles of free thiols/mg of SR; most are located on CaATPase pumps but are not oxidized by RDSs. RDSs served to measure stoichiometrically the number of thiol sites oxidized on SR vesicles. The oxidation of free thiol(s) on RyRs can result in disulfide bond formation with either (i) the exogenously added RDS, (ii) vicinal thiols located on RyRs, or vicinal thiols located on other triadic proteins.

\section{OXIDATION-REDUCTION GATES THE SINGLE CHANNEL ACTIVITY OF RYRs}

Several studies have shown that RDS increase the single-channel activity of RyRs reconstituted in planar bilayers by increasing the 
open probability to near 1 . Oxidation of critical thiols by $2,2^{\prime}$ DTDP and $4,4^{\prime}$ DTDP was first demonstrated in a 106-kDa ryanodine-sensitive channel incorporated in planar bilayers (Zaidi et al., 1989b; Hilkert et al., 1992), and then in cardiac RyRs (Eager et al., 1997) and mammalian and amphibian skeletal receptors (Marengo et al., 1998). These studies showed that RDS produced an increase in mean open probability of channels in low cis- $\mathrm{Ca}^{2+}$ that was inhibited by $\mathrm{Mg}^{2+}$ and ATP (Hilkert et al., 1992; Eager and Dulhunty, 1998). These results suggested a physical interaction between the ATP-binding domain on the RyR complex and cysteine residues that regulate ion channel gating mechanisms (Eager et al., 1997; Eager and Dulhunty, 1999).

\section{REACTIVE DISULFIDES TRIGGER SR $\mathrm{Ca}^{2+}$ RELEASE FROM SKELETAL AND CARDIAC MUSCLE}

The highly selective nature of RDS for low $\mathrm{pKa}$ thiols was confirmed by showing that RDSs at 2-10 $\mu M$ elicited a rapid release of $\mathrm{Ca}^{2+}$ from the SR network of skinned psoas fibers, with no signs of interactions with thiols on myosin ATPase or creatine kinase (Zaidi et al., 1989a). Posterino and Lamb (1996) challenged the validity of these results because under their conditions, RDSs did not induce SR $\mathrm{Ca}^{2+}$-release. They argued that Salama et al. (1992) used low $\mathrm{Mg}^{2+}$ and "EGTA-skinned" fibers, which result in $\mathrm{Ca}^{2+}$ overload of the SR and hyperexcitable fibers that are likely to release $\mathrm{Ca}^{2+}$ at the slightest perturbation. However, Salama et al. (1992) examined the actions of heavy metals and cysteine plus copper and analyzed the force response of the fibers as a function of free $\left[\mathrm{Mg}^{2+}\right](0.04,0.1,0.4$, and 1.5 $\left.\mathrm{mM}\left[\mathrm{Mg}^{2+}\right]_{\text {free }}\right)$. The EGTA-skinning procedure thoroughly depletes $\mathrm{SR} \mathrm{Ca}{ }^{2+}$ because the fibers are washed in $1 \mathrm{mM}$ EGTA for days and it is necessary to reload the SR before measuring CICR contractions. Zaidi et al. (1989a) showed that high ATP inhibits RDS-induced $\mathrm{Ca}^{2+}$ release, whereas Posterini and Lamb (1996) experiments were carried out with $8 \mathrm{mM}$ ATP. The combination of reduced ATP and $\mathrm{Mg}^{2+}$ made it possible to compare the ampli- tude and kinetics of CICR and sulfhydryl-induced $\mathrm{Ca}^{2+}$ release (Zaidi et al., 1989a). CICR contractions had stable baselines, did not contract spontaneously, and had rapid rise and equally rapid recoveries as for contractions elicited by $2,2^{\prime}$ DTDP. These contractions had kinetics that could not be misconstrued as spontaneous $\mathrm{Ca}^{2+}$ release from an overloaded SR. Posterino and Lamb (1996) observed that high levels of $2,2^{\prime}$ DTDP $(100 \mu M)$ interfered with depolarization-induced $\mathrm{Ca}^{2+}$ release by acting at the myofibrils. Contrary results were obtained in collaboration with Dr. Franklin Fuchs (University of Pittsburgh). RDSs were tested in rabbit psoas and bovine ventricular muscles treated with Triton $X-100$ to examine direct interactions with the contractile apparatus. The force versus $\mathrm{pCa}$ relationship was not altered by $2,2^{\prime}$ DTDP in the range of $5-100 \mu M$.

Skinned fibers serve only as models of physiological excitation-contraction coupling, and the conditions used by Posterino and Lamb (1996) do not withstand close scrutiny. For instance, contractions elicited by ionic substitutions are presumably caused by a depolarization of $T$ tubules. However, there are no measurements of voltage across the "resealed" $T$ tubules, no estimates of the heterogeneity or the percentage of $\mathrm{T}$ tubules that reseal to generate a membrane potential. The substitution of $\mathrm{K}^{+}$HDTA to choline chloride is thought to depolarize T tubules with no effect on the SR network. However, choline induces $\mathrm{Ca}^{2+}$ release from heavy SR vesicles and SR of skinned rabbit psoas fibers and may not be suitable to investigate the communication between the voltage-sensor and the RyR (Patel et al., 1996). Another note of caution is that all solutions should be passed through Chelex columns to remove heavy-metal contamination and avoid their interaction with sulfhydryls (Salama et al., 1992). Posterino and Lamb (1996) assumed a heavy metal contamination of $\leq 3.5 \mu M$ due to EGTA, but heavy metals act at considerably lower values $\left(\mathrm{IC}_{50}=10^{-14} \mathrm{M}\right.$ free $\mathrm{Hg}^{2+}$ induces $\mathrm{Ca}^{2+}$ release) and most heavy metals bind to thiols with greater affinity than to EGTA (Salama et al., 1992).

To bypass concerns about the "physiological validity" of skinned fiber preparations, we tested the effects of 2,2'DTDP on intact mouse 
diaphragms that were attached to a force transducer and electrically stimulated ( $2 \mathrm{msec}$ duration, $0.2 \mathrm{~Hz}, 2 \times$ threshold). As shown in Fig. 1 , an addition of 2,2'DTDP $(20 \mu M)$ produced an increase in tonic force and a slight decrease in twitch force. A second addition of 2,2'DTDP $(50 \mu M)$ caused a further increase in baseline force. Twitch force decreased due to the decrease of $\mathrm{Ca}^{2+}$ load in the SR, but 2,2'DTDP did not block twitches (i.e., E-C coupling). Higher levels of 2,2'DTDP $(100 \mu M)$ caused a greater rise of force that was reversed by $10 \mathrm{mM}$ DTT (Fig. 1B). The elevation of force induced by $2,2^{\prime}$ DTDP was measured in the absence of added external $\mathrm{Ca}^{2+}$, was inhibited by inhibitors of RyRs, which indicated that $\mathrm{Ca}^{2+}$ was released from internal stores and specifically through the activation of RyRs. The addition of DTT (5-10 $\mathrm{mM})$ reversed the effects of $2,2^{\prime} \mathrm{DTDP}$, indicating that sulfhydryl oxidation-reduction of RyRs was the underlying mechanism. In Fig. 1C-E, RDSs elicited SR $\mathrm{Ca}^{2+}$ release and a tonic rise in cytosolic $\mathrm{Ca}^{2+}$ (Cai) in cardiomyocytes and perfused guinea pig hearts loaded with a $\mathrm{Ca}^{2+}$ indicator. The Cai elevation was due to the oxidation of RyR that was reversed by DTT ( $1 \mathrm{mM})$ (Fig. 1C) and inhibited by ruthenium red $(5 \mu M)$ (Menshikova and Salama, 1998).

\section{BIPHASIC ACTIONS OF THIOL OXIDANTS ON CHANNEL ACTIVITY}

Heavy metals and cysteine plus $\mathrm{Cu}^{2+}$ have been found to activate SR $\mathrm{Ca}^{2+}$ release at low concentrations and then inactivate release at high concentrations (Moutin et al., 1989; Salama et al., 1992). Salama et al. (1992) proposed a sulfhydryl gating mechanism consisting of "activating" and "inhibitory" thiol sites of high and low reactivity. In this model, sulfhydryl oxidants would first oxidize "activating" thiol residues, which might then expose the "inhibitory" thiols that when oxidized result in channel closure (Salama et al., 1992). The biphasic actions of RDS were confirmed in planar bilayers where $4,4^{\prime}$ DTDP was shown first to increase the open probability of RyRs and then to close the channel at still higher concentrations or as a function of time (Eager and Dul- hunty, 1999). RDSs appeared to interact with three classes of cysteines. Two of these thiols are associated with opening of the release channel, whereas one thiol at high concentrations of RDSs promotes channel closure (Eager and Dulhunty, 1999).

\section{NITRIC OXIDE}

The studies discussed above support the idea that pathological conditions alter the redox potential and channel activity of RyRs but do not identify a physiological sulfhydryl oxidant that might regulate RyRs and $\mathrm{Ca}^{2+}$ handling. We first examined authentic nitric oxide (NO, NO gas), but the concentrations of $\mathrm{NO}$ needed to elicit SR $\mathrm{Ca}^{2+}$ release were too great to be biologically significant. In contrast, we showed for the first time that NO donors oxidize RyRs, resulting in an increase in open probability of the channel and $\mathrm{Ca}^{2+}$ release from skeletal and cardiac SR vesicles (Stoyanovsky et al., 1997). NO elicited SR $\mathrm{Ca}^{2+}$ release at $60-200 \mu M$ and at $200-400 \mu M$ in deoxygenated and oxygenated solutions, respectively. This is in line with the expected interaction of $\mathrm{NO}$ with $\mathrm{O}_{2}$ to form $\mathrm{N}_{2} \mathrm{O}_{3}$, which interacts with $\mathrm{H}_{2} \mathrm{O}$ to neutralize $\mathrm{NO}$ to $\mathrm{NO}_{3}$ (Kharitonov et al., 1995). However, in the presence of cysteine $(50 \mu \mathrm{M}), 60 \mu \mathrm{M}$ NO emptied the SR of its releasable $\mathrm{Ca}^{2+}$, even in oxygenated solutions (Stoyanosky et al., 1997). The potentiation of $\mathrm{NO}$ by cysteine in oxygenated solutions is consistent with the predicted interaction of $\mathrm{NO}$ and $\mathrm{O}_{2}$ to form $\mathrm{N}_{2} \mathrm{O}_{3}$, which can readily nitrosylate low-molecularweight thiols in the cytosol, like cysteine and glutathione, to form R-SNO compounds (Kharitonov et al., 1995). Thiol-containing NO-donors (cys-NO $=S$-nitrosocysteine and $\mathrm{SNAP}=\mathrm{S}$-nitrosopenicillamine) then act through a direct exchange or transnitrosylation of $\mathrm{NO}$ from the donor to the RyR. Channel activation could occur through the nitrosylation of critical sulfhydryl sites on RyRs, resulting in the formation of stable S-nitrosothiols (S-NO) residues or transient S-NO bonds followed by disulfide bond formation with vicinal thiols on RyRs. Sulfhydryl reducing agents (e.g., GSH, DTT) reversed the effects of $2,2^{\prime}$ DTDP and NO to promote channel closure. DTT and GSH are 
A.
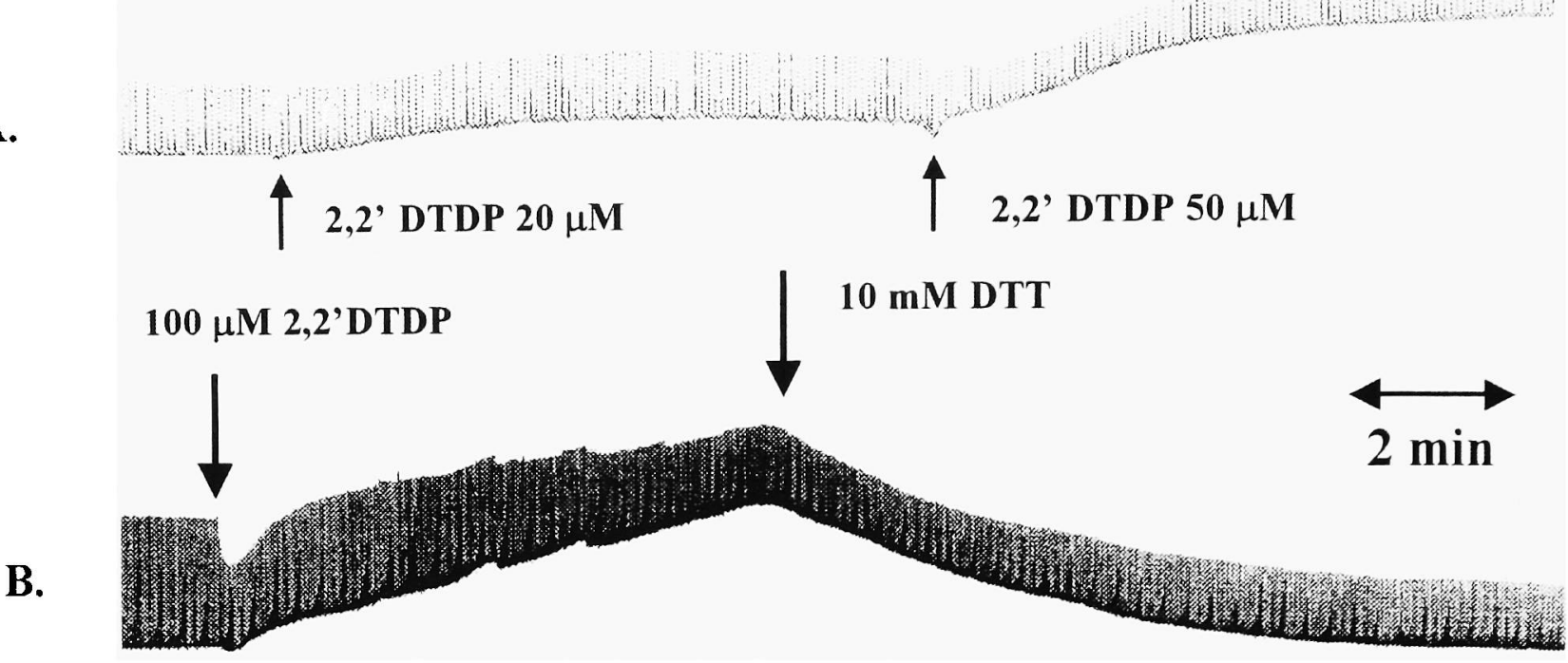

c.
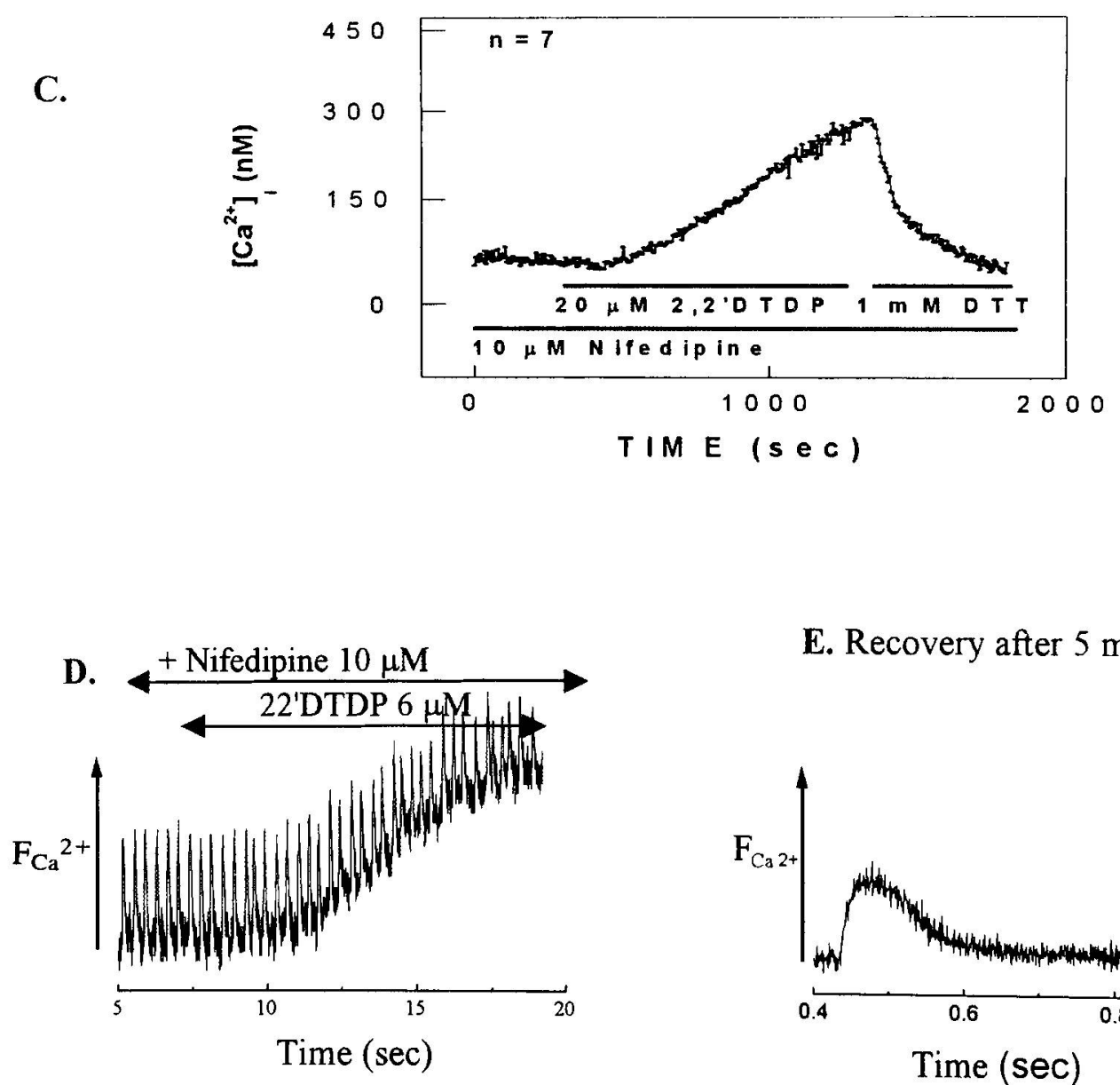

E. Recovery after $5 \mathrm{~min}$

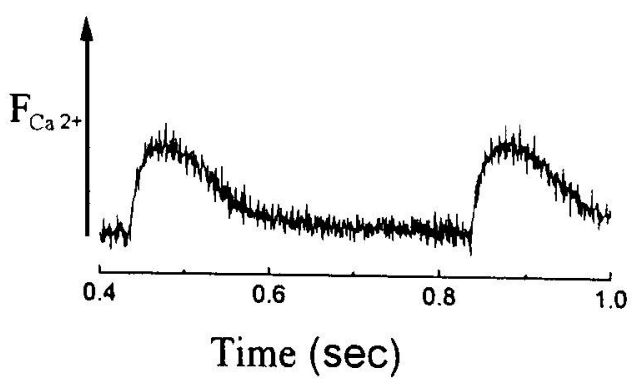


expected to be equally effective at reducing SNO or S-S bonds, and hence, cannot be used to distinguish between the two products of NO oxidation. By analogy to other SH oxidants, $\left[{ }^{3} \mathrm{H}\right]$ ryanodine binding to $\mathrm{SR}$ vesicles was inhibited as a function of NO (cys-SNO) concentration, and the $\mathrm{Ca}^{2+}$-ATPase activity of skeletal and cardiac SR was not influenced by NO (Stoyanosky et al., 1997).

Meszaros et al. (1996) reported an opposite effect in which SNAP inhibits RyRs whereas mercaptoethanol restores channel activity, and they attributed this observation to an interaction of NO with sulfhydryl sites on RyRs. The inactivation of the channel by an oxidant (SNAP) and its reactivation by a reductant (mercaptoethanol) is opposite to all previous reports and were not reproducible (Stoyanosky et al., 1997). L-Arginine in the presence of NO synthase generates $\mathrm{NO}$ and was found to inhibit caffeine induced $\mathrm{Ca}^{2+}$ release from skeletal SR vesicles and decrease the open probability of cardiac RyRs in planar bilayers (Meszaros et al., 1996; Zahradnikova et al., 1997). Inhibition of caffeine induced SR $\mathrm{Ca}^{2+}$ release by SNAP is questionable because the effect was modest and fell well within the experimental variability of this release process (Meszaros et al., 1996; Stoyanovsky et al., 1997). On the other hand, the marked decrease ( $>10$-fold) in the open probability of cardiac RyRs by NO (from L-arginine plus eNOS) could be significant, even though the levels of NO were not determined (Zahradnikova et al., 1997). However, Xu et al. (1998) only detected increased levels of channel activation from purified cardiac RyRs in planar bilayers as a function of $S$ - polynitrosylation of the protein and failed to detect an inhibition of channel activity by NO donors.

Aghdasi et al. (1997) attempted to reconcile the controversy of whether or not NO inactivates or activates RyRs by proposing that low levels of NO inactivate and high levels activate the receptor. Their conclusions were based on the multiple classes of sulfhydryls with which $\mathrm{N}$-ethylmaleimide (NEM) could interact, resulting in activation, inactivation, and then reactivation of RyRs, as a function of time and [NEM]. In turn, NO inhibited NEM-induced $\mathrm{Ca}^{2+}$ release at low concentrations, but NO directly activated RyRs at high concentrations. The binding of NEM to various fragments of RyRs served as further evidence that NEM interacted at multiples classes of thiol sites on RyRs through an alkylation of protein thiols, a reaction that is not reversed by reducing agents. However, NEM tends to react with thiol at high substrate concentrations ( $\mathrm{mM}$ ) and is not selective because it can interact with amino and carboxyl moieties (Brocklehurst, 1979). As shown in Fig. 2A, NEM elicits $\mathrm{Ca}^{2+}$ release from skeletal SR vesicles at $\geq 20 \mu M$, but the reactions at low and high concentrations are different. At low NEM, the release is fully reversed by adding DTT $(1 \mathrm{mM})$, which indicates that NEM did not alkylate a thiol group. At high NEM concentrations, $\mathrm{Ca}^{2+}$ release was not reversed by DTT, as expected for an alkylation of thiol sites. Moreover, the effects of low [NEM] could be washed out by centrifuging and resuspending the vesicles in NEM-free medium. As shown in Fig. 2B, NO donors do not reverse the effects of $100 \mu \mathrm{M} \mathrm{NEM}$, whereas

FIG. 1. RDS elicit SR Ca ${ }^{2+}$ release in striated muscle. A and B. Mouse diaphragms were bathed in Tyrode's solution containing zero external $\mathrm{Ca}^{2+}$ and then were paced electrically while measuring force with a tension transducer. Addition of 2,2'DTDT resulted in a rise in baseline or tonic force and caused a decrease in twitch tension. In B, DTT $(10 \mathrm{mM})$ reversed the effect of $2,2^{\prime} \mathrm{DTDP}(100 \mu \mathrm{M})$. The data indicate that the $\mathrm{RDS}^{\mathrm{alicits}} \mathrm{Ca}^{2+}$ release from internal stores via a sulfhydryl oxidation. C. RDSs increase intracellular free $\mathrm{Ca}^{2+}$ (Cai) in isolated cardiomyocytes. Rat cardiomyocytes were loaded with Fura-2 and treated with nifedipine $(10 \mu M)$ to block $\mathrm{Ca}^{2+}$ entry via voltagegated L-type $\mathrm{Ca}^{2+}$ channels. An addition of $2,2^{\prime} \mathrm{DTDP}(20 \mu M)$ elicited a rise in Cai and DTT (1 mM) reversed this effect. The trace is the averaged response of seven myocytes measured in one experiment. The trace is representative of five independent experiments where each experiment monitored 4-12 myocytes. D and E. Effect of 2,2'DTDP on Cai in perfused guinea pig hearts. A guinea pig heart was loaded with Rhod-2/AM to measure Cai from the epicardium. An excitation beam $\left(\lambda_{\mathrm{ex}}=520 \pm 30 \mathrm{~nm}\right)$ illuminated the heart and the Rhod- 2 emission $\left(\lambda_{\mathrm{em}}=585 \pm 20 \mathrm{~nm}\right)$ measured cytosolic $\mathrm{Ca}^{2+} \cdot 2,2^{\prime}$ DTDP elicited $\mathrm{Ca}^{2+}$ release from the SR, which was reversed by DTT. Nifedipine reduced the amplitude of Cai transients during cardiac contractions, but 2,2'DTDP elevated Cai through the oxidation of cardiac RyRs. 

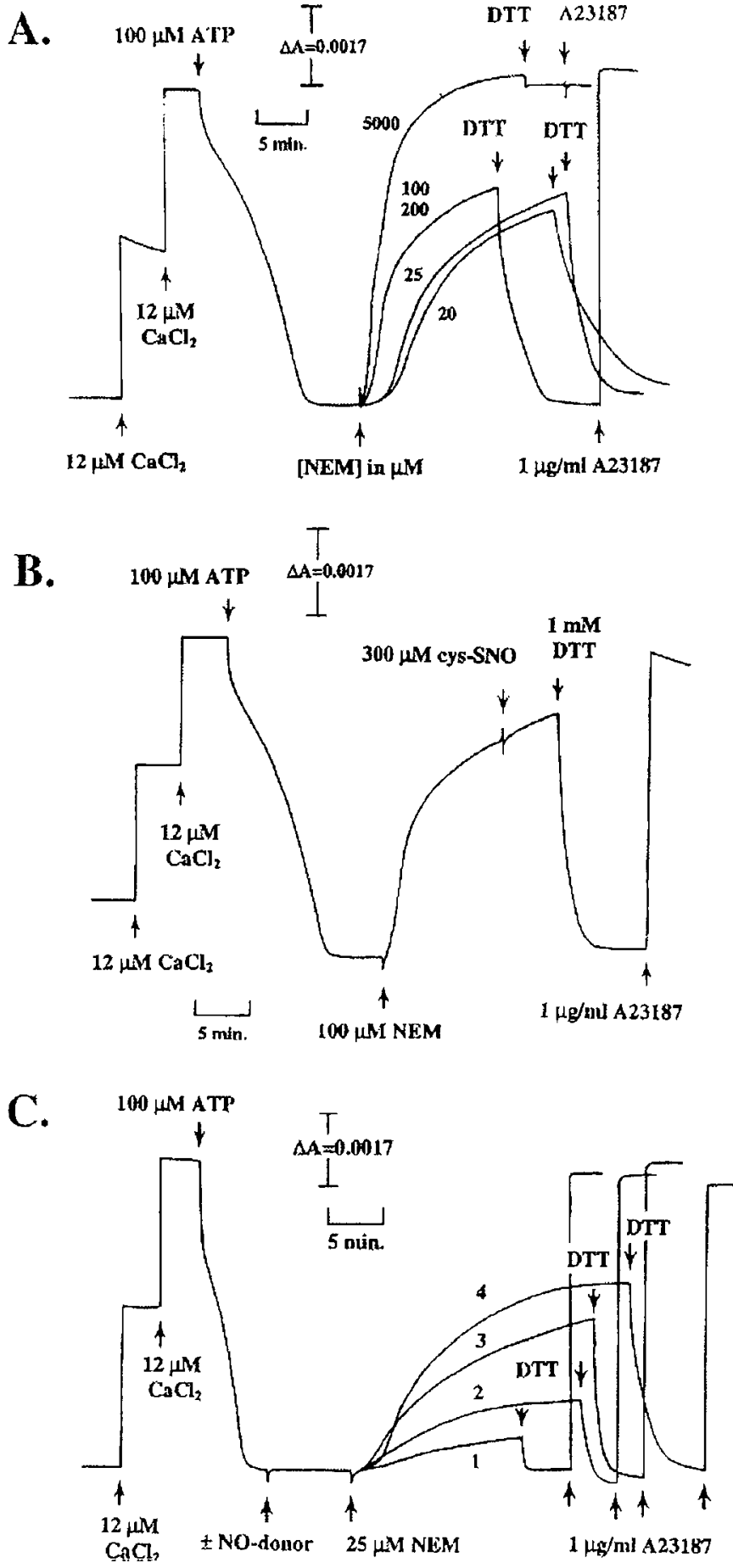

FIG. 2. $N$-Ethylmaleimide (NEM) does not act at sulfhydryl sites on $\mathrm{SR}$ vesicles. $\mathrm{Ca}^{2+}$ transport across $\mathrm{SR}$ vesicles was determined by measuring extravesicular free $\left[\mathrm{Ca}^{2+}\right]$ through the differential absorption changes of Antipyrylazo III at 720-790 $\mathrm{nm}$. SR vesicles $(0.2 \mathrm{mg} / \mathrm{ml})$ were actively loaded with $\mathrm{Ca}^{2+}$ using an ATP-regenerating system and then NEM was added to the reaction mixture at various concentrations to elicit $\mathrm{Ca}^{2+}$ release. After release was completed, DTT was added to reverse the effects of the NEM. A23187 was added to measure the total releasable $\mathrm{Ca}^{2+}$ from the vesicles. A. Two aliquots of $\mathrm{Ca}^{2+}(12 \mu \mathrm{M})$ were added, then ATP $(100 \mu M)$ was added to initiate $\mathrm{Ca}^{2+}$ uptake. NEM $(20-5,000 \mu M)$ elicited $\mathrm{Ca}^{2+}$ release from the vesicles. DTT $(1 \mathrm{mM})$ reversed the effect of low levels of NEM resulting in the re-uptake of $\mathrm{Ca}^{2+}$ by SR. If NEM acts at sulfhydryl sites, it would alkylate the cysteine residue, resulting in a covalent bond that cannot be reversed by DTT. The reversibility of NEM-induced $\mathrm{Ca}^{2+}$ release indicates that NEM did not act at a thiol site but is likely to undergo a reversible ionic interaction. In agreement with that interpretation, NEM could also be washed out resulting in a reversal of its effect. The most likely explanation is that DTT interacts directly with NEM to reverse NEM-induced $\mathrm{Ca}^{2+}$ release. B. $\mathrm{Ca}^{2+}$ release was induced by NEM (100 $\mu M)$; however, cys-SNO (300 $\mu M)$ did not reverse this effect whereas DTT ( $1 \mathrm{mM})$ induced the re-uptake of $\mathrm{Ca}^{2+}$ by SR. C. $\mathrm{Ca}^{2+}$ release induced by low [NEM] could be inhibited but not blocked by NOdonors. SR vesicles were pretreated with NOdonor with, respectively, traces 1-4: (1) $300 \mu M$ SNAP; (2) $300 \mu M$ NOC-15 (PAPA-NONOate); (3) $10 \mu M$ cys-SNO; (4) control followed by NEM ( 25 $\mu M)$. The NO donors inhibited NEM-induced $\mathrm{Ca}^{2+}$ release and DTT $(1 \mathrm{mM})$ in a full reversal, resulting in $\mathrm{Ca}^{2+}$ re-uptake by SR vesicles.
DTT did. When an NO donor is added at a concentration too low to cause release, the subsequent NEM-induced $\mathrm{Ca}^{2+}$ release is inhibited but not fully blocked (Fig. 2C). In this case, NO appears to be interacting directly with NEM, decreasing its effective concentration rather than inhibiting the release channel. Other studies have reported that NO can protect against lipid peroxidation and sulfhydryl oxidation such as the interaction of NO with potent oxidant like hydroperoxides (Gorbunov et al., 1998; Menshikova et al., 1999). 


\section{ROLE OF SULFHYDRYL OXIDATION-REDUCTION IN HEALTH AND DISEASE}

In the vast majority of isolated SR studies, it is commonly ignored that the cellular environment is highly reduced. The redox potential of the cell is maintained at a large negative potential by a large excess of reduced GSH over its oxidized form (GSSG). Reduced GSH at concentrations similar to that found in the cell inhibits RyR1 and decreases the open probability of the reconstituted $\mathrm{Ca}^{2+}$ release channel, whereas the addition of oxidized GSSG strongly activates the receptor (Zable et al., 1997). Alterations of the cellular redox potential during oxidative stress, such as occurs during ischemia, reperfusion, cardiac myopathies, aging, and muscle fatigue, are likely to have profound effects on the gating characteristics of the RyR. Moreover, whether or not the redox potential of this receptor is influenced by the cellular environment $\left(\mathrm{Ca}^{2+}, \mathrm{Mg}^{2+}\right.$, nucleotide concentration) or the degree of oxidative stress is not fully resolved.

Several studies have now implicated changes in redox state of RyRs as part of the disease phenotype. In papillary muscles of cardiomyopathic Syrian hamsters, the force of contraction and the rate of relaxation were suppressed compared to control muscles. The addition of a membrane-permeable sulfhydryl reducing agent ( $N$-acetyl-cysteine) produced a positive ionotropic effect and improved cardiac contractility (Finkle et al., 1992, 1993). The sulfhydryl-dependent positive ionotropic effect was observed in cardiac myopathy but not in control muscles and was associated with changes of $\left[{ }^{3} \mathrm{H}\right]$ ryanodine binding. The data indicated that a defect in the redox state of RyRs in myopathic hamsters could account for the contractile dysfunction. Several studies have shown that in acute ischemia (30-60 min), SR vesicles isolated from ischemic ventricular muscle transport and retain less $\mathrm{Ca}^{2+}$ than vesicles from normal tissue, but the precise mechanism remains controversial (see review by Zucchi and Ronca-Testoni, 1997). More recent studies suggest that the altered sulfhydryl redox state in ischemia may contribute to isch- emic preconditioning (Zucchi et al., 1998). Our studies recently showed that SR vesicles isolated from ischemic dog or human hearts (posttransplantation) accumulated less $\mathrm{Ca}^{2+}$ than controls and that the addition of a sulfhydryl reducing agent increased the rate and net uptake of $\mathrm{Ca}^{2+}$ by $~ 50 \%$ (Salama et al., 1996; Kagan et al., 1998). Moreover, the angiotensin converting enzyme (ACE) inhibitor captopril was shown to be an effective membrane-permeable sulfhydryl reducing agent that reversed ischemia-induced oxidation of cardiac RyRs (Salama et al., 1996).

\section{MOLECULAR INTERACTION OF NO AND RyRs}

The cloning, expression and reconstitution of RyRs derived from skeletal muscle SR (RyR1) has shown that the RyR consists of homologous tetramers of $M_{r} \sim 565 \mathrm{kDa}$ with four transmembrane domains near the carboxyl-terminal end and a large cytosolic foot process at the amino-terminal end (Takeshima et al., 1989). We investigated the interaction(s) between $\mathrm{NO}$ and RyR by expressing truncated forms of RyRs that are derived from the carboxy-terminal region of rabbit RyR1 and applying mutations at key cysteine residues. Chinese hamster ovary cells $(\mathrm{CHO})$ were transfected with expression plasmids for the full-length (p565) or truncated, $M_{r} \sim 170(\mathrm{p} 170)$ or $M_{r} \sim 75(\mathrm{p} 75)$ RyR (Takeshima et al., 1993) resulting in marked expression of these proteins in the endoplasmic reticulum (ER), as indicated with immunofluorescence analysis and Western blots. Transfected CHO cells were loaded with Fura 2 to measure Cai and to test for functional RyRs through $\mathrm{Ca}^{2+}$ release from the ER elicited by caffeine, ryanodine, NO donors, or sulfhydryl oxidants. Ryanodine $(10 \mu M)$ did not alter Cai in control cells but increased Cai in cells transfected with p565, p170, or p75. Caffeine did not alter Cai in controls, but it did elicit a release of $\mathrm{Ca}^{2+}$ from cells transfected with p565 and p170 but not with p75. NO donors and the sulfhydryl oxidant, 2,2'-DTDP increased Cai in control CHO cells, and the effect was blocked by heparin, an inhibitor of $\mathrm{Ca}^{2+}$ release from inositol $(1,4,5)$ triphosphate 
receptors $\left(\mathrm{IP}_{3}-\mathrm{Rs}\right)$. In the presence of heparin, DTDP and NO donors elicited ER $\mathrm{Ca}^{2+}$ release from $\mathrm{CHO}$ cells transfected with p565, p170, and p75. NO-induced $\mathrm{Ca}^{2+}$ release was similar in its kinetics and the extent of Cai elevation when $\mathrm{CHO}$ cells were transfected with fulllength or $p 75$ truncated receptors. Furthermore, thiol-dependent $\mathrm{Ca}^{2+}$ release was inhibited by ryanodine $(100 \mu M)$, tetracaine $(0.2$ $\mathrm{m} M)$, or ruthenium red $(5 \mu M)$, indicating that release occurred via cloned channels expressed in the ER. Hence, the truncated p75 receptors ( $<14 \%$ of the full-length RyR) from the carboxy-terminal end of RyR1 contain the pore of the channel, and retain ryanodine, thiol oxidation, and NO-dependent activation of the channel but lose caffeine sensitivity (Menshikova et al., 1998b). Truncated p75 RyRs contain nine cysteine residues of which only two, C4958 and C4961, lie in a domain that is conserved in the known isoforms of RyRs. Preliminary experiments revealed that a C4958A mutation resulted in a loss of channel sensitivity to NO and sulfhydryl oxidation. Thus, truncated RyRs and site-directed mutagenesis offer a unique approach to elucidate the structure-function relationship of this large receptor and will help identify the precise cysteine residue involved in redox regulation of the channel.

\section{ABBREVIATIONS}

ACE, angiotensin converting enzyme; Cai, ionized calcium; $\mathrm{CHO}$, Chinese hamster ovary cells; CICR, $\mathrm{Ca}^{2+}$ induced $\mathrm{Ca}^{2+}$ release; CysNo, S-nitrosocysteine; 2,2'-DTDP, 2,2'dithiopyridine; DTT, dithiothreitol; ER, endoplasmic reticulum; GSH, reduced glutathione; GSSG, oxidized glutathione; HDTA, potassium hexamethylene-diamine-tetra acetate; $\mathrm{IP}_{3}$-Rs, inositol $(1,4,5)$ triphosphate receptors; NEM, $N$ ethylmaleimide; NO, nitric oxide; RDS, reactive disulfide compounds; RyR, ryanodine receptors; $\mathrm{SH}$, sulfhydryl group; S-NO, S-nitrosothiols; SNAP, S-nitroso- $N$-acetyl-penicillamine; $\mathrm{SR}$, sarcoplasmic reticulum.

\section{REFERENCES}

ABRAMSON, J.J., and SALAMA, G. (1987). Regulation of the sarcoplasmic reticulum permeability by sulfhydryl oxidation and reduction. J. Membr. Sci. 33, 241-248.

ABRAMSON, J.J., and SALAMA, G. (1988). Sulfhydryl oxidation and $\mathrm{Ca}^{2+}$ release from sarcoplasmic reticulum. Mol. Cell. Biochem. 82, 81-84.

ABRAMSON, J., TRIMM, J.L., WEDEN, L., and SALAMA, G. (1983). Heavy metals induce rapid calcium release from sarcoplasmic reticulum vesicles isolated from skeletal muscle. Proc. Natl. Acad. Sci. USA 80, 1526-1530.

ABRAMSON, J.J., BUCK, E., SALAMA, G., CASIDA, J.E., and PESSAH, I.N. (1988a). Mechanism of anthraquinone induced $\mathrm{Ca}^{2+}$ release from skeletal muscle sarcoplasmic reticulum. J. Biol. Chem. 263, 18750-18758.

ABRAMSON, J.J., CRONIN, J., and SALAMA, G. (1988b). Oxidation induced by phthalocyanine dyes causes rapid $\mathrm{Ca}^{2+}$ release from sarcoplasmic reticulum vesicles. Arch. Biochem. Biophys. 263, 245-255.

ABRAMSON, J.J., and SALAMA, G. (1989). Critical sulfhydryls regulate calcium release from sarcoplasmic reticulum. J. Bioenerget. Biomembr. 21, 283-294.

ABRAMSON, J.J., MILNE, S., BUCK, E., and PESSAH, I.N. (1993). Porphyrin induced calcium release from skeletal muscle sarcoplasmic reticulum. Arch. Biochem. Biophys. 301, 396 403.

ABRAMSON, J.J., ZABLE, Z.C., FAVERO, T.G., and SALAMA, G. (1995). Thimerosal interacts with the $\mathrm{Ca}^{2+}$ release channel ryanodine receptor from skeletal muscle sarcoplasmic reticulum. I. Biol. Chem. 270, 29644-29647.

AGHDASI, B., REID, M.B., and HAMILTON, S.L. (1997). Nitric oxide protects the skeletal muscle $\mathrm{Ca} 2+$ release channel from oxidation induced activation. J. Biol. Chem. 10, 272:25462-25467.

AOKI, T., OBA, T., and HOTTA, K. (1985). $\mathrm{Hg}^{2+}$ induced contracture in mechanically skinned fibers of frog skeletal muscle. Can. J. Physiol. Pharmacol.63, 1070-1074.

BROCKLEHURST, K. (1979). Specific covalent modification of thiols: applications in the study of enzymes and other biomolecules. Int. J. Biochem. 10, 259-274.

CAVALLINI, D., DEMARCO, D., DUPREE, S., and RORIOLO, G. (1969). The copper catalyzed oxidation of cysteine to cystine. Arch. Biochem. Biophys. 130, 354-361.

EAGER, K.R., and DULHUNTY, A.F. (1998). Activation of the cardiac ryanodine receptor by sulfhydryl oxidation is modified by $\mathrm{Mg}^{2+}$ and ATP. J. Membr. Biol. 163, 9-18.

EAGER, K.R., and DULHUNTY, A.F. (1999). Cardiac ryanodine receptor activity is altered by oxidizing reagents in either the luminal or cytoplasmic solution. J. Membr. Biol. 167, 205-214.

EAGER, K.R., RODEN, L.D., and DULHUNTY, A.F. (1997). Actions of sulfhydryl reagents on single ryanodine receptor $\mathrm{Ca}(2+)$-release channels from sheep myocardium. Am. J. Physiol. 272, C1908-C1918.

FAVERO, T.G., ZABLE, A., and ABRAMSON, J.J. (1995). Hydrogen peroxide stimulates the $\mathrm{Ca}^{2+}$ release channel from sarcoplasmic reticulum. J. Biol. Chem. 270, 25557-25563. 
FENG, W., LIU, G., ABRAMSON, J.J., XIA, R., and PESSAH, I.N. (1999). Site-selective modification of hyperreactive thiols on ryanodine receptor complex by quinones. Mol. Pharmacol. 55, 821-831.

FINKEL, M.S., SHEN, L., ROMEO, R.C., ODDIS, C.V., and SALAMA, G. (1992). Radioligand binding and ionotropic effects of ryanodine in the cardiomyopathic Syrian hamster. J. Cardiovasc. Pharmacol. 19, 610-617.

FINKEL, M.S., ODDIS, C.V., ROMEO, R.C., and SALAMA, G. (1993). Positive inotropic effect of acetylcysteine in the cardiomyopathic Syrian hamster. J. Cardiovasc. Pharmacol. 21, 29-34.

GORBUNOV, N.V., TYURINA, Y.Y., SALAMA, G., DAY, B.W., CLAYCAMP, H.G., ARGYROS, G., ELSAYED, N.M., and KAGAN, V.E. (1998). Nitric oxide protects cardiomyocytes against tert-butyl hydroperoxide-induced formation of alkoxyl and peroxyl radicals and peroxidation of phosphatidylserine. Biochem. Biophys. Res. Commun. 244, 647-651.

GOULD, G.W., COLYER, J., EAST, J.M., and LEE, A.G. (1987). Silver ions trigger $\mathrm{Ca}^{2+}$ release by interaction with the $\left(\mathrm{Ca}^{2+}-\mathrm{Mg}^{2+}\right)$-ATPase in reconstituted systems. 262, 7676-7679.

HILKERT, R., ZAIDI, N.F., SHOME, K., NIGAM, M., LAGENAUR, C., and SALAMA, G. (1992). Properties of immuno-affinity purified $106-\mathrm{kDa} \mathrm{Ca}^{2+}$ release channels from skeletal sarcoplasmic reticulum. Arch. Biochem. Biophys. 292, 1-15.

KAGAN, V.E., RITOV, V.B., GORBUNOV, N.V., MENSHIKOVA, E., and SALAMA, G. (1998). Oxidative stress and $\mathrm{Ca}^{2+}$ transport in skeletal and cardiac sarcoplasmic reticulum. In: Oxidative Stress in Skeletal Muscle. A. Reznick, ed. (Birkhäuser Verlag Basel, Switzerland) pp. 181-199.

KHARITONOV, V.G., SUNDQUIST, A.R., and MA, V.S. (1995). Kinetics of nitrosation of thiols by nitric oxide in the presence of oxygen. I. Biol. Chem. 270, 28158-28164.

LAI, F.A., ERICKSON, H.P., ROUSSEAU, E., LIU, Q.Y., and MEISSNER, G. (1998). Purification and reconstitution of the calcium release channel from skeletal muscle. Nature 331, 315-319.

MARENGO, J.J., HIDALGO, C., and BULL, R. (1998). Sulfhydryl oxidation modifies the calcium dependence of ryanodine-sensitive calcium channels of excitable cells. Biophys. J. 74, 1263-1277.

MENSHIKOVA, E.V., and SALAMA, G. (1998). Reactive disulfides elevate cytosolic free $\mathrm{Ca}^{2+}$ in cardiomyocytes by oxidizing regulatory thiols on ryanodine receptors (RyRs). Circulation 98, I-805.

MENSHIKOVA, E.V., LIU, C., TAKESHIMA, H., and SALAMA, G. (1998b). Truncated (170 and $75 \mathrm{kD}$ ) ryanodine receptors form $\mathrm{Ca}^{2+}$ release channels sensitive to ryanodine, thiol reagents and nitric oxide. Circulation 98, I-402.

MENSHIKOVA, E.V., RITOV, V.B., GORBUNOV, N.V., SALAMA, G., CLAYCAMP, G., and KAGAN, V.E. (1999). Nitric oxide prevents myoglobin/tert-butylhydroperoxide-induced inhibition of $\mathrm{Ca}^{2+}$ transport in skeletal and cardiac sarcoplasmic reticulum. Annals NY Acad. Sci. USA 874, 370-385.
MESZAROS, L.G., MINAROVIC, I., and ZAHRADNIKOVA, A. (1996). Inhibition of the skeletal muscle ryanodine receptor calcium release channel by nitric oxide. FEBS Lett. 380, 49-52.

MOUTIN, M.J., ABRAMSON, J.J., SALAMA, G., and DUPONT, Y. (1989). Rapid $\mathrm{Ag}^{+}$-induced release of $\mathrm{Ca}^{2+}$ from sarcoplasmic reticulum vesicles of skeletal muscle: a rapid filtration study. Biochim. Biophys. Acta 984, 289-292.

OBA, T., and HOTTA, K. (1985). Silver ion-induced tension development and membrane depolarization in frog skeletal muscle fibres. Pflugers Arch. 405, 354-359.

OBA, T., IWAMA, H., and AOKI, T. (1989). Ruthenium red and magnesium ion partially inhibit silver ion-induced release of calcium from sarcoplasmic reticulum of frog skeletal muscles. Jpn. J. Physiol. 39, 241-254.

PALADE, P. (1987). Drug-induced $\mathrm{Ca}^{2+}$ release from isolated sarcoplasmic reticulum. II. Releases involving a $\mathrm{Ca}^{2+}$-induced $\mathrm{Ca}^{2+}$ release channel. J. Biol. Chem. 262, 6142-6148.

PATEL, J.R., SUKHAREVA, M., CORONADO, R., and MOSS, R. (1996). Chloride-induced $\mathrm{Ca}^{2+}$ release from the sarcoplasmic reticulum of chemically skinned rabbit psoas fibers and isolated vesicles of terminal cisternae. J. Membr. Biol. 154, 81-89.

PESSAH, I.N., STAMBUCK, R.A., and CASIDA, J.E. (1987). $\mathrm{Ca}^{2+}$-activated ryanodine binding: mechanisms of sensitivity and intensity modulation by $\mathrm{Mg}^{2+}$, caffeine and adenine nucleotides. Mol. Pharmacol. 31, 232-238.

POSTERINO, G.S., and LAMB, G.D. (1996). Effects of reducing agents and oxidants on excitation-contraction coupling in skeletal muscle fibres of rat and toad. J. Physiol. (Lond.) 496, 809-825.

PRABHU, S., and SALAMA, G. (1990a). Reactive disulfide compounds induce $\mathrm{Ca}^{2+}$ release from cardiac sarcoplasmic reticulum. Arch. Biochem. Biophys. 282, 275-283.

PRABHU, S., and SALAMA, G. (1990b). The heavy metals $\mathrm{Ag}^{+}$and $\mathrm{Hg}^{2+}$ trigger $\mathrm{Ca}^{2+}$ release from cardiac sarcoplasmic reticulum vesicles. Arch. Biochem. Biophys. 277, 47-55.

SALAMA, G., and ABRAMSON, J.J. (1984). Silver ions trigger $\mathrm{Ca}^{2+}$ release by acting at the apparent physiological $\mathrm{Ca}^{++}$-release site in sarcoplasmic reticulum vesicles. J. Biol. Chem. 259, 13363-13369.

SALAMA, G., ABRAMSON, J.J., and PIKE, G.K. (1992). Sulfhydryl reagents trigger $\mathrm{Ca}^{2+}$ release from the sarcoplasmic reticulum of skinned skeletal muscle fibers, J. Physiol. (Lond.) 454, 389-420.

SALAMA, G., CHOI, B.-R., HEIN, M.C., MENSHIKOVA, E., and ABRAMSON, J.J. (1996). The ACE inhibitor Captopril inhibits $\mathrm{Ca}^{2+}$ release from cardiac and skeletal sarcoplasmic reticulum (SR) by reducing critical thiols on ryanodine receptors (RyR). Biophys. J. 70, A257.

SMITH, J.S., IMAGAWA, T., MA, J., FILL, M., CAMPBELL, K.P., and CORONADO, R. (1988). Purified ryanodine receptor from rabbit skeletal muscle is the calcium-release channel of sarcoplasmic reticulum. J. Gen. Physiol. 92, 1-26.

STOYANOVSKY, D., MURPHY, T., ANNO, P.R., KIM, 
Y.-M., and SALAMA, G. (1997). Nitric oxide activates skeletal and cardiac ryanodine receptors. Cell Calcium 21, 19-29.

STUART, J., PESSAH, I.N., FAVERO, T.G., and ABRAMSON, J.J. (1992). Photooxidation of skeletal muscle sarcoplasmic reticulum induces rapid calcium release. Arch. Biochem. Biophys. 292, 512-521.

TAKESHIMA, H., NISHIMURA, S., MATSUMOTO, T., ISHIDA, H., KANGAWA, K., MINAMINO, N., MATSUO, H., UEDA, M., HANAOKA, M., HIROSE, T., and NUMA, S. (1989). Primary structure and expression from complimentary DNA of skeletal muscle ryanodine receptor. Nature 339, 439-445.

TAKESHIMA, H., NISHIMURA, S., NISHI, M., IKEDA, M., and SUGIMOTO, T. (1993). A brain-specific transcript from the 3'-terminal region of the skeletal muscle ryanodine receptor gene. FEBS Lett. 322, 105-110.

TRIMM, J., SALAMA, G., and ABRAMSON, J.J. (1986). Sulfhydryl oxidation triggers $\mathrm{Ca}^{2+}$ release from sarcoplasmic reticulum vesicles. I. Biol. Chem. 261, 16092-16098.

XIONG, H., BUCK, E., STUART, J., PESSAH, I.N., SALAMA, G., and ABRAMSON, J.J. (1992). Rose bengal activates the $\mathrm{Ca}^{2+}$ release channel from skeletal muscle sarcoplasmic reticulum. Arch. Biochem. Biophys. 292, 522-528.

XU, L., EU, J.P., MEISSNER, G., and STAMLER, J.S. (1998). Activation of the cardiac calcium release channel (ryanodine receptor) by ply-S-nitrosylation. Science 279, 234-237.

ZABLE, A.C., FAVERO, T.G., and ABRAMSON, J.J. (1997). Glutathione modulates ryanodine receptor from skeletal muscle sarcoplasmic reticulum. Evidence for redox regulation of the $\mathrm{Ca}^{2+}$ release mechanism. J. Biol. Chem. 272, 7069-7077.

ZAHRADNIKOVA, A., MINAROVIC, I., VENEMA, R.C., and MESZAROS, L.G. (1997). Inactivation of the car- diac ryanodine receptor calcium release channel by nitric oxide. Cell Calcium 22, 447-454.

ZAIDI, N.F., LAGENAUR, C., PESSAH, I.N., ABRAMSON, J.J., and SALAMA, G. (1989a). Reactive disulfide reagents trigger $\mathrm{Ca}^{2+}$ release from skeletal sarcoplasmic reticulum. J. Biol. Chem. 264, 21725-21736.

ZAIDI, N.F., LAGENAUR, C., XIONG, H., ABRAMSON, J.J., and SALAMA, G. (1989b). Disulfide linkage of biotin identifies a $106 \mathrm{kDa} \mathrm{Ca}^{2+}$ channel in skeletal sarcoplasmic reticulum. J. Biol. Chem. 264, 21737-21747.

ZUCCHI, R., and RONCA-TESTONI, S. (1997). The sarcoplasmic reticulum $\mathrm{Ca}^{2+}$ channel/ryanodine receptor: Modulation by endogenous effectors, drugs and disease states. Pharmacol. Rev. 49, 1-51.

ZUCCHI, R., YU, G., GALBANI, P., MARIANI, M., RONCA, G., and RONCA-TESTONI, S. (1998). Sulfhydryl redox state affects susceptibility to ischemia and sarcoplasmic reticulum $\mathrm{Ca}^{2+}$ release in rat heart. Implications for ischemic preconditioning. Circ. Res. 83, 908-915.

Address reprint requests to: Dr. Guy Salama Professor of Cell Biology and Physiology University of Pittsburgh, School of Medicine 3500 Terrace Street S314 Biomedical Science Tower 3400 Terrace Street Pittsburgh, Pennsylvania 15261

E-mail: gsalama+@pitt.edu

Received for publication August 1, 1999; accepted November 12, 1999. 


\section{This article has been cited by:}

1. Lufang Zhou, Miguel A. Aon, Ting Liu, Brian O'Rourke. 2011. Dynamic modulation of Ca2+ sparks by mitochondrial oscillations in isolated guinea pig cardiomyocytes under oxidative stress. Journal of Molecular and Cellular Cardiology . [CrossRef]

2. Scott K. Powers, Li Li Ji, Andreas N. Kavazis, Malcolm J. JacksonReactive Oxygen Species: Impact on Skeletal Muscle . [CrossRef]

3. David J. Duncan, Zhaokang Yang, Philip M. Hopkins, Derek S. Steele, Simon M. Harrison. 2010. TNF-\# and IL-1\# increase Ca2+ leak from the sarcoplasmic reticulum and susceptibility to arrhythmia in rat ventricular myocytes. Cell Calcium 47:4, 378-386. [CrossRef]

4. Dr. Livia C. Hool , Ben Corry . 2007. Redox Control of Calcium Channels: From Mechanisms to Therapeutic Opportunities. Antioxidants \& Redox Signaling 9:4, 409-435. [Abstract] [PDF] [PDF Plus]

5. S. N. Grishin, A. V. Shakirzyanova, A. Yu. Teplov, I. M. Fatkhutdinov, V. V. Valiullin, A. L. Zefirov. 2006. Mechanism of N-ethylmaleimide-induced contraction of the frog sartorius muscle. Bulletin of Experimental Biology and Medicine 141:3, 278-280. [CrossRef]

6. Rubin I. Cohen, David Wilson, Shu Fang Liu. 2006. Nitric oxide modifies the sarcoplasmic reticular calcium release channel in endotoxemia by both guanosine-3???,5??? (cyclic) phosphate-dependent and independent pathways*. Critical Care Medicine 34:1, 173-181. [CrossRef]

7. Elisabeth R. Barton, Linda Morris, Masataka Kawana, Lawrence T. Bish, Thierry Toursel. 2005. Systemic administration ofL-arginine benefitsmdx skeletal muscle function. Muscle \& Nerve 32:6, 751-760. [CrossRef]

8. Hsueh-meei Huang, Hui Zhang, Hsiu-Chong Ou, Hua-Lian Chen, Gary E. Gibson. 2004. \#KETO-ß-METHYL-n-VALERIC ACID DIMINISHES REACTIVE OXYGEN SPECIES AND ALTERS ENDOPLASMIC RETICULUM Ca2+ STORES. Free Radical Biology and Medicine 37:11, 1779-1789. [CrossRef]

9. Stephen D. Tichenor, Nicholas A. Malmquist, Iain L.O. Buxton. 2003. Dissociation of cGMP accumulation and relaxation in myometrial smooth muscle: effects of S-nitroso-N-acetylpenicillamine and 3morpholinosyndonimine. Cellular Signalling 15:8, 763-772. [CrossRef] 